\title{
Value Co-Creation in Branding Social Marketing Services: An Exploratory Study
}

\author{
Syed Ali Raza Hamid*, Muhammad Kamran Naqi Khan \\ International Islamic University, Islamabad, Pakistan \\ Hamdard University, Islamabad Campus, Pakistan \\ *alirazahamid@gmail.com
}

\begin{abstract}
The study intends to determine how informally social pioneering initiative in terms of value cocreation gets transformed into vibrant social brands having credibility and sustainable dimensions. This phenomenon is critical to study in order to advance the body of knowledge of social marketing, particularly in context to branding social causes. The rationale for continuing with conventional approaches reinforces model ways of thinking in social marketing. This is one of the reasons that several efforts were made to promote development programs like Millennium Development Goals, Non-smoking, and environmental conservation have barely come to fruition. Lack of success or failure could only be attributed due to lack of conceptual advancement and developing innovative techniques to transform the creative ideas of social marketing into practices. This research transcends the traditional approaches taking group rather than individual as a unit of analysis. An exploratory study has been conducted to find out what are the major determinants, ideas and thoughts that transform social pioneering initiatives in to a credible brand. The study confirms that value co-creation is a function of transcendental values that people experience while interacting and consuming social marketing services.
\end{abstract}

Keywords: Social Marketing, Co-creation, Value, Branding, behavior

\section{Introduction}

One of the major concerns of Social Marketing Services is to address social issues with the premise of behavior change and formation while applying the tools and techniques of marketing. With this perspective, the growth in the field of social marketing reflects an uneven tendency because the field has hardly seen a substantial outcome in terms of effectively harnessing behavior towards social agendas. But with the sound policy framework and strategies, the desired outcomes of social marketing may be produced (Haynes et al., 2012). Though principal scholars in the field of marketing such as Kotler and Zaltman (1971) have been putting constructive inputs in favor of social aspects; many other scholars had been refuting the stance of the said scholars stating marketing as a solitary tool which deals consumerism and customer satisfaction. Polonsky et al. (1999) have postulated that the field of marketing should entertain other stakeholders in addition to consumers to hold the vitality of the field. As model and discipline, the consideration of social aspects in marketing has been an emerging field of enquiry since the evolution of marketing has started (Wilkie \& Moore, 1999). Now the literature has reached to a level where it has sharpen the vision that tend to ask some important questions that need to be addressed so that the field must earn its practical importance in the eyes of policy makers, practitioners, as well as academicians (Lefebvre, 2011). Since then from this thought provoking work by the lead scholars, it has been observed that Social Marketing has significantly expanded in its scope and dimensions to enhance quality of people, programs, healthcare, and community development (Andreasen, 2005). There are some challenging aspects of social marketing:

A. One of the major issues which is crucial for sustenance and maintenance of social cause is generating desired amount of donations to meet the cause (Zainuddin, 2011). It has, however, a critical factor but has always been addressed, by and large, through commercial approaches using marketing principles (Kotler \& Lee, 2008), rather making donors and community or beneficiary as an active participant in the exchange process of social marketing who serves as value co-creator (Lefebvre, 2012).This in turn, creates the desired level of confidence and trust prerequisite to sustain the social marketing program. This could only be handled if a requisite supportive system is engendered, which is prerequisite to create value of the program in the eyes of the concern stakeholders and reinforce their confidence, to enhance their commitment in terms of financial support. In other words, if beneficiaries are real terms 
yield of the program that improve their quality of life would certainly be the major force to create become value (Austin, 2010).

Co-creation acts as an advocate for the mechanism of social marketing which is truly enduring to the viability of social marketing services. This kind of thought will also strongly associate with the beneficiary and communities to create an image which will be transformed into a social marketing brand. This way of translating others' actions into rhetoric (Middleton \& Edwards, 1989) is rooted in social constructionist point of view. This way brand is socially constructed and this process of construction and identification is very much rooted into the interactive experiences of consumers and community as a reputable brand. If we draw some experiences of many social services in Pakistan as well as internationally, it is quite evident that a very few social services have earned real success in terms of achieving status of trustworthy brands; though they never started a program with a perspective of developing a brand. It is, however, the social ethos to serve sincerely and selflessly to a disadvantaged and impoverished segment of the society. Albeit, some of these organizations turned out to be billion dollar operations that they cater from sustainable growth of their donations from the public to reinforce their welfare activities. Moreover, with sense of mission, relentless and selfless efforts have transformed some notable organizations like Edhi Trust and Shaukat Khanum cancer Hospital have evolved as international social brands of high standing. On contrary to the statement made by Keller (1998) in his article, these social services in Pakistan turned into brands by their credible actions, which are delivered practically in public rather than developing themes and slogan prior to the commencement of service.

B. To transcend the approach, a traditional methodology of brand management system will have to be modified, to promote social marketing programs or services. It is quite evident from the current researches that there is a clear shift of power from managerial approaches to social marketing to implement the programs towards participatory and interactive experiences of consumers and society. Moreover, many social service organizations fail to meet their social goals like millennium development goals MDGs (GPA, 2010a). One of the reasons is lack of government commitment and requisite substantial financial support from the government.

C. This research has intended to find out what were the major determinants of ideas and thoughts that transform into branding social services in the social circle.

Multiple social marketing services in advanced countries are rendering services in different areas of the society specifically targeting pro social behaviors. Masses are aware of the beneficial acquisition of the services but even in those advanced countries of the world, governments and policy makers have not fully explored the scope of services in domain of social marketing. As a result, a partial segment of the society is not aware of their social benefits or does not bother to use that social marketing service (Haynes et al., 2012). Considering the objectives of the present study, there remains a significant room to establish what the field of social marketing can comprehensively offer through embedding co creation and branding concepts. Because branding echoes a collective, value co-creation activity of firm and its stakeholders (Vargo et al., 2009).

Since value creation is not an independent process which takes place during its course of development rather it employs an iterative approach (Gronroos \& Voima, 2013) which further gives rise to value co creation. Exploring this concept will advance the realm of social marketing services by exploring new aspects which are crucial for social marketing. Thus the primary objective of this study is to determine the ideas and thoughts that transform social marketing services into credible brand.

\section{Literature Review}

Social Marketing Services: The literature has served as an eye opener for researchers that tend to ask some important questions (Dibb \& Carrigan, 2013), which are mainly about the effectiveness of application of social marketing programs. Social Marketing Services around the world are known and recognized of their utmost benefits for contributing in the welfare of society. The agenda of these Social Marketing Services is not restrained to the conventional marketing paradigm rather they primarily aim to form a robust attitude and behavior change where the cause under consideration can become a social good. It has however, been reported in several researches that social marketing campaigns have been partially taking commercial 
marketing approaches and eventually the campaigns are no longer regarded as social in nature (Agha \& Armand, 2006). However, society's wellbeing in the form of adopting every rational step deemed beneficial for it is adhered to the practices and principles of social marketing (Haynes et al., 2012). Though addressing those social issues would imply somewhat different approaches from commercial marketing but since all social causes at which social marketing services are aimed have connection with individuals and groups, therefore it is pertinent to mention here that in order to highlight the social issues caused by the individual or human behavior i.e. aligned with the principles of marketing but the application is different as to polish that human behavior ready to embrace a social good(Hastings \& Saren, 2003). Here Social Marketing Services' role remains imperative.

Orientation of Value Co-creation: Multifarious Social Marketing Services through their actions do not ensure a thorough behavior change. The main attention of these kinds of services is attached with the services of donors who play a critical role in uplifting the services' image and performance (Mackay, 2002). The contribution by sponsors and donors is an important facet in marketing giving brand identity to any social marketing program (Olsen \& Hill, 2006). Here the current research has tried to explore the idea of value co-creation which reflects in collaboration and interaction of all possible stakeholders who are acquiring social services. Social Network Theory also advocates the phenomenon of interaction among the stakeholders thus creating the impact of value co-creation on the outcome of social marketing services. Value co-creation is a seminal concept that is being researched in the realm of contemporary marketing (Grönroos, 2010). It endeavors to include the role of all the stakeholders of Social Marketing Services who participate and experience such services (Prahalad \& Ramaswamy, 2004). The research tends to establish through qualitative research that what are the ways that requisite stakeholders adopt while using Social Marketing Services in experiencing and reciprocating value (Terblanche, 2014).

Branding Social Marketing Services: Employing traditional strategies of marketing could reap stronger results that maybe witnessed in branding any Social Marketing Service and behaviors these services seek to change (Neiger \& Thakeray, 2001). This aspect has been construed as instrumental in inducing brand. The notion of branding in social marketing is of paramount importance since the purpose of branding is to communicate to the target audience the distinct images of a service making the service successful in terms of its diffusion and adoption. The cases of Edhi Trust, Shaukat Khanum, Akhuwat Foundation, and Green star campaigns can be well documented in Pakistan that how these social services eventually transformed into social brands leaving universal impact of serving the humanity in the backdrop of social marketing. Social Marketing Services need recognition and known to be a part of social processes because communities and other stakeholders are always involved in such proposition which create a brand like image of such services and place confidence in using brands either they relate to service or a product. This phenomenon further implies that value co creation is a collaborative process involving firms, stakeholders and the services rendered as social brand (Ballantyne \& Aitken, 2007). However, the concept of branding in Social Marketing Services has been scarcely used despite knowing the attributes that branding provides to social marketing program. A few Social Marketing Services in Pakistan such as Edhi Trust and Shaukat Khanum elucidate their transformation towards social brand as a result of interaction and participation activities.

\section{Methodology}

The study has been conducted in conjunction with branding of leading social services and the philosophies and procedures of the leading Social Marketing Services such as Shaukat Khanum, Edhi Foundation and Akhuwat Foundation. The proposed methodology has been employed as grounded theory approach (Glaser, 1998) which intends to incorporate the leading social marketing services as brands and through their shared values and actions interpreting the notion. The study reflects the espoused social services coupled with co creation activities. The identified factors analyzed the contents through focus group, checked through the literature of social marketing, to advance conceptual knowledge of branding in social marketing services. It will turn into a grounded theory. Further it needs empirical testing. The study has been conducted in twin cities of Islamabad and Rawalpindi where the subjects who should be referred to as focus groups were included and their opinions and beliefs of the said services have been drawn to formulate a theoretical framework for branding social marketing services. All four focus groups were selected meticulously considering their ages, education, perception and knowledge about the social services they have been 
experiencing. These focus groups comprised of 60 people from different age brackets and from various professions like law, medicine, business, and higher education. The study took approximately six months to design and execute. Primarily an interview schedule was employed and the responses of the participants were noted in detail. Each session with the respondents' amounted to about one and a half hour where all the individuals were supposed to give their valuable views on multiple social services operating in the country. Upon completion of discussion with focus groups, all the conversation was thoroughly analyzed and commonalities were chosen as dimensions to include in the framework of branding Social Marketing Services.

Table 1: Demographic Characteristics of the Participants

\begin{tabular}{|c|c|c|c|}
\hline $\begin{array}{l}\text { Demographic Variable } \\
\text { Age }\end{array}$ & $\begin{array}{l}\text { Category } \\
23-30\end{array}$ & $\begin{array}{l}\text { Frequency } \\
25\end{array}$ & $\begin{array}{l}\text { Percentage } \\
42\end{array}$ \\
\hline & $30-40$ & 20 & 33 \\
\hline & $40-50$ & 15 & 25 \\
\hline \multicolumn{4}{|l|}{ Gender } \\
\hline Male & 40 & 67 & \\
\hline Female & 20 & 33 & \\
\hline \multicolumn{4}{|l|}{ Education } \\
\hline Undergraduate & 20 & 33 & \\
\hline Graduate & 40 & 67 & \\
\hline \multicolumn{4}{|l|}{ Profession } \\
\hline Service People & 20 & 33 & \\
\hline Lawyers & 03 & 05 & \\
\hline Doctors & 02 & 03 & \\
\hline Businessmen & 03 & 05 & \\
\hline Students & 32 & 53 & \\
\hline
\end{tabular}

Table 2: Item list related to focus group discussion

In your opinion, what is brand?

Why do you buy a brand?

How can you value a service as brand?

Do you know social service which markets itself as welfare oriented?

Have you found any social marketing service Action oriented?

unethical practices?

Do services play a role in forming positive behavior so as to discourage socially

What is a good social service?

Why will you believe the credibility of a social service?

Why social service becomes important?

How can you form an organization like Edhi?

How can a social service become prominent?

How can social services become humane?

\section{Results}

Primarily twelve items were included in the interview schedule to elicit an opinion about social services and whether the respondents view them as brands. Forty male respondents and twenty female respondents participated in the session. Other demographics related to the participants are listed in table 1 . From the given items, first order theme and second order theme have been drawn which are shown in the figure.

In your opinion, what is brand? To this question, the focus group responded mentioning the purity of products and services as a factor that compelled them to buy a brand. Also personal preference was identified by the participants as a dimension for brand purchase. Trust was also identified as being the amount of 
confidence people place in using a service or product. All four focus groups had much in common while responding to this particular question.

Why do you buy a brand? In responding to this question, belief, patronage, utility and satisfaction were commonly thought of as determinants of buying a brand.

How can you value a service as brand? This question drew humanitarian goals, preservation of beneficiary's ego, fame and honesty of the service as ideas behind perceived value. All the participants of different focus groups had commonly answered these attributes of a valued service.

Do you know a social service which markets itself as welfare oriented? The respondents opined that a social service which markets itself as a welfare oriented organization strictly follows check and balance in its entire system and ensures there is no discrepancy in its system. Similarly, that kind of service always keeps itself open for scrutiny and has its system transparent. The organization never keeps its beneficiaries unaware of the activities it performs.

Have you found any social marketing service action-oriented? The participants responded linking positive social action to law abidance. In their opinion, most of the services in the country which are action-oriented always abide by laws; they also have support from the media and are known for their social acceptance. Therefore, law abidance, support from media, and social identity are the determinants of an action-oriented social service.

Do services play a role in forming positive behavior so as to discourage socially unethical practices? First of all, a service should be religiously aware of its rights and obligations. According to respondents, if a service has religiosity as part of its mission; it cannot have chances of misleading people. Then household culture and customs play a pivotal role in determining behavior. Therefore, services should target individuals and their customs with a view to educating them to bring about positive behavior. Since humans learn by observation and imitate (Bandura, 1962) their surroundings, positive behavior would be replicated and emulated.

What is a good social service? 'Good' was identified as corruption free. Respondents had views that a corruption free service is one which can be trusted with blind faith. Being corruption free is the most important determinant which makes a social service 'good' in the eyes of people. In addition, availability of services as and when required by people is what makes a service reliable and trustworthy. Availability here refers to immediate help rendered by the service to the recipient. Also participants said that the simpler the service, the more trusted it is.

Why will you believe the credibility of a social service? The participants thought that all veteran and old services were credible. In addition to this a credible social service is always hard working and activities are measured purely on humanitarian grounds.

Why does a social service become important? The key factor was identified as presence of leadership quality in its management. Secondary factors were the service's concern for people, devotion in its job and sense of belongingness to society.

How can you form an organization like Edhi? To form such an organization, positivity was the most important consideration, followed by philanthropic interest, constructive approach, accountability, and environmental hygiene.

How can a social service become prominent? The respondents collectively added that indiscrimination in addressing people's needs and professional relations are important determinants of a prominent service.

How can a social service become more philanthropic? Participants from all focus groups generally thought that a service free from personal interests would be more philanthropic. If a social service works on selfless basis it would certainly gain people's confidence. It should also deal people on the basis of a collectivist approach. 


\section{Figure 1: Theoretical Propositions}

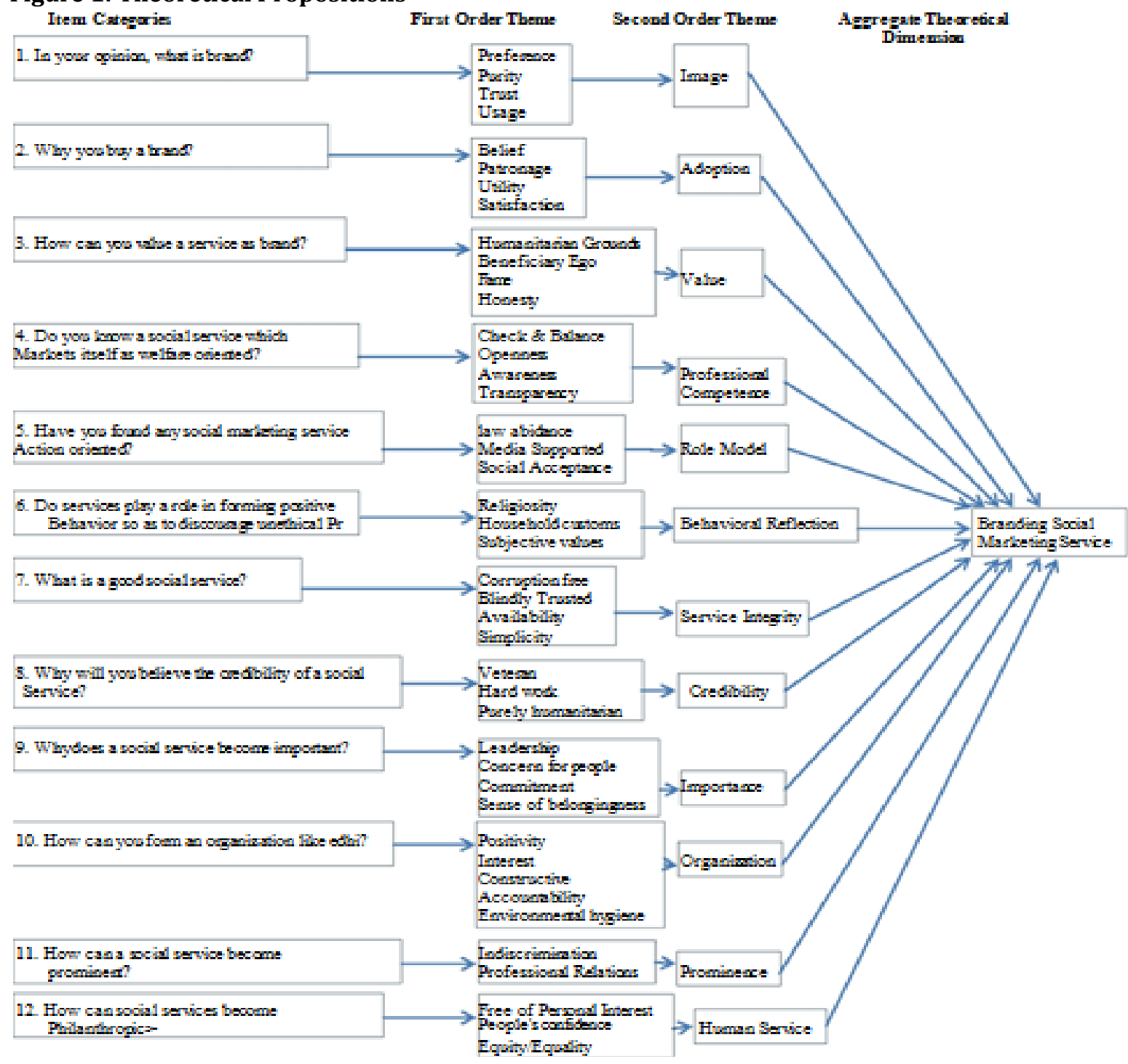

\section{Discussion}

According to the definition of AMA (2007), value is embedded in most constituents of commercial marketing thus integrating the former with social marketing. As co-creator of value, sponsors of social services contribute implicitly in branding but it is hard to determine how this aspect of value is perceived by others. It has been asserted in this paper that social services operating locally are perceived as social brands due to the actions these services perform; since these kind of services are fewer in number and this conception by the people is contrary to Keller's statement in his article of 1998 where he termed valuing immediate benefits of desirable behavior a challenge for branding in social marketing services. Apparently, where quality and result oriented services are scarce in number, they make an impact and value in the minds of people. This helps such services in achieving a brand status. In societies where action oriented social services are numerous and where effective government welfare programs exist side by side, a social service will have to be outstanding in some aspect in order to become a brand. In such an environment, a social service would have to lean upon media services to propagate its strengths in the eyes of public.

When assessing the value of Social Marketing Services, the role of multifarious actors like individuals and the resources involved are inevitable to be studied as no single actor can be the initiator or determinant of value 
but it is co-constructed (Prahalad \& Ramaswamy, 2004). Thus considering the norms of value co-creation in branding Social Marketing Services would be a tipping point. The data from the survey and interviews has been analyzed in a number of steps. The qualitative data has been furnished and reviewed which further identified issues related to Social Marketing Services. This research draws attention of policy makers and Social Marketing Services towards issues being faced by them with the help those who are beneficiaries and active members of community.

Limitations: Although quite an interesting outcome about branding social services has come forth. This study has taken into account focus groups having healthy amount of knowledge about the services. Whereas people working on behalf of social services should also have been included so as to draw another opinion about branding social services. Also people from only two cities cannot present the ideas which prove to be fruitful for effective Social Marketing Services.

\section{References}

Agha, S. M. \& Armand, F. (2006). When donor support ends. The fate of social marketing products and the markets they help create. Social Marketing Quarterly, 12(2), 28-42.

AMA. (2007). Proposed 2007 Definition of Marketing, Web-based survey of membership, (May 1-3), (accessed August 1, 2007), [available at http://www.surveymonkey.com/s.asp?u=169153797122].

Andreasen, A. R. (2005). Social Marketing in the Twenty-first Century, Sage, Thousand Oaks, CA.

Austin, J. (2010). From Organization to Organization: On Creating Value. Journal of Business Ethics, 94, 13-15.

Ballantyne, D. \& Aitken, R. (2007). Branding in B2B Markets: Insights from the Service-Dominant Logic of Marketing. Journal of Business and Industrial Marketing, 22(6), 363-371.

Bandura, A. (1962). Social learning through imitation. In M. R. Jones (Ed). Nebraska Symposium on Motivation. Lincoln: Univer. Nebraska Press, 1962, Pp. 211 - 269.

Dibb, S. \& Carrigan, M. (2013). Social marketing transformed Kotler, Polonsky and Hastings reflect on social marketing in a period of social change. European Journal of Marketing, 47(3), 1376-1398.

Glaser, B. (1998). Doing Grounded Theory: Issues and Discussions, Sociology Press, Mill Valley, CA.

GOP. (2010a). Planning Commission. Pakistan Millennium Development Goals Report 2010.Retrievedfrom: http://www.pc.gov.pk/mdgspak2010.html.

Grönroos, C. \& Vioma, P. (2013). Critical service logic: making sense of value creation and co-creation. J. of the Acad. Mark. Sci., 41, 133-150DOI 10.1007/s11747-012-0308-

Grönroos, C. (2010). A service perspective on business relationships: The value creation, interaction and marketing interface Industrial Marketing Management.

Hastings, G. \& Saren, M. (2003). The critical contribution of social marketing: theory and application. Marketing Theory, 3(3), 305-322.

Haynes, L., Service, O., Goldacre, B. \& Torgerson, D. (2012). Test, Learn, Adapt: developing public policy with randomized controlled trials, Policy Paper published by the Cabinet Office Behavioral Insights Team, available at: www.cabinetoffice.gov.uk

Keller, K. L. (1998). Branding Perspectives on Social Marketing. Advances in Consumer Research

Kotler, P. \& Lee, N. (2008). Social marketing: Influencing behaviors for good. Los Angles: Sage.

Kotler, P. \& Zaltman, G. (1971). Social marketing: an approach to planned social change. Journal of Marketing, 35(3), 3-12.

Lefebvre, R. C. (2011). An integrative model for social marketing. Journal of Social Marketing, 1(1), 54-72

Lefebvre, R. C. (2012). Transformative social marketing: co-creating the social marketing discipline and brand. Journal of Social Marketing, 2(2), 118-129.

Mackay, B. (2002). Social marketing brands: Who owns them and does it matter? Bath, England: Futures Group Europe.

Middleton, D. \& Edwards, D. (1989). Collective remembering. London: Sage.

Olsen, L. K. \& Hill, R. P. (2006). The Impact of Sponsor Fit on Brand Equity. The Case of Nonprofit Service Providers. Journal of Service Research, 9(1), August 2006 73-83

Polonsky, M. J., Suchard, H. T. \& Scott, D. R. (1999). The Incorporation of an Interactive External Environment: A Stakeholder Approach. Journal of Strategic Marketing, 7(1), 41-55

Prahalad, C. K. \& Ramaswamy, V. (2004). Co-creation experiences: the next practice in value creation. $J$ Interact Market, 18(3), 5-14. 
Neiger, B. L. \& Thackeray, R., M. (2001). Positioning Social Marketing as a Planning Process for Health Education. American Journal of Health Studies, 18(2/3).

Terblanche, N. S. (2014). Some theoretical perspectives of co-creation and co-production of value by customers. Acta Commercii, 14(2), Art No. 237. http://dx.doi.org/10.4102/ac.v14i2.237.

Vargo, S. L., Morgan, F. W., Akaka, M. \& He, Y. (2009). The service-dominant logic of marketing: a review and assessment. Review of Marketing Research, 6, in press.

Wilkie, W. L. \& Moore, E. S. (1999). Consortium Survey on Marketing and Society Issues: Summary and Results. Journal of Macro marketing, 17 (2), 89-95.

Zainuddin, N. (2011). Value Co-Creation in Social Marketing Wellness Services. Available from http://eprints.qut.edu.au/47995/1/Nadia_Zainuddin_Thesis.pdf. 